\title{
IMMUNOHISTOCHEMICAL STUDY OF GAMMA-GLUTAMYL TRANSPEPTIDASE WITH MONOCLONAL ANTIBODIES II. AN IMMUNOELECTRON MICROSCOPIC STUDY IN RAT KIDNEY*
}

\author{
Shuji YAMAShita, Sadakazu AISO, Masahide SHIOZAWA \\ AND Kenjiro YASUDA \\ Department of Anatomy, School of Medicine Keio University, Shinanomachi-35, \\ Shinjuku, Tokyo 160
}

Received for publication March 6, 1989 and in revised form April 24, 1989

\begin{abstract}
The localization of gamma-glutamyl transpeptidase ( $\gamma$-GTP) in the rat kidney was examined by immunoelectron microscopy using monoclonal antibody to rat $\gamma$ GTP. The enzyme was distributed along the brush border and in the apical canaliculi and vacuoles of the proximal tubules. The immunoreaction of $\gamma$-GTP in the brush borders increased from the $S_{1}$ to $S_{3}$ segments in the proximal tubules. Conspicuous $\gamma$-GTP immunostaining was observed along the basolateral membranes of the $S_{2}$ and $S_{3}$ segments of the proximal tubules. In addition, the apical cell membrane of the upper part of descending thin limbs of Henle's loops exhibited positive $\gamma$-GTP immunostaining. A faint reaction was occasionally recognized in the apical cell membranes of the distal convoluted cells, including the macula densa.
\end{abstract}

$\gamma$-GTP (EC 2.3.2.2) is an essential enzyme for the metabolism of glutathione (2, 20). It is involved in the degradation of glutathione by hydrolysis of the $\gamma$-glutamyl moiety or by transferring it to other amino acids or peptides. This enzyme is a membrane-bound glycoprotein which is composed of heavy and light subunits $(10,12,22$, $30,31)$.

$\gamma$-GTP is distributed in the epithelial cells of many tissues $(6,16,20)$. The higher $\gamma$-GTP activity is found in the kidney $(8,20) . \quad \gamma$-GTP has been identified in the brush border membrane of proximal tubular cells of the kidney by biochemical $(4,6)$ and enzyme histochemical methods (5, 14-16, 25). The enzyme histochemical technique has the advantage of demonstrating the $\gamma$-GTP enzyme activity in the cells in situ. However, it has the following limitations as regards the precise localization of the enzyme: 1) the final reaction products are diffusible; and 2) it is incapable of being applied to electron microscopic studies because the final reaction products are soluble in organic solvents (25). Recent immunohistochemical studies with polyclonal antibodies have indicated that $\gamma$-GTP is present not only in the brush borders $(17,22$, $28,29)$ but also in the basolateral membranes $(23,28)$ of the proximal convoluted tubule cells. However, few examinations of the localization of $\gamma$-GTP have been

\footnotetext{
* This study was supported in part by Grant-in-Aid for Scientific Research from the Ministry of Education, Science and Culture, Japanese Government No. 61480093 and 63870002.
} 
reported for other nephronic tubules (23).

Monoclonal antibody, which recognizes a single determinant with a high specificity, is expected to permit a more precise determination of the localization of $\gamma$-GTP. We previously prepared monoclonal antibodies to rat $\gamma$-GTP which reacted with the heavy subunit of the enzyme (32): the heavy subunit is an anchor portion to the cell membranes $(10,30,31)$. This report describes the localization of $\gamma$-GTP in rat renal nephronic tubules based on immunoelectron microscopy using monoclonal antibody.

\section{MATERIALS AND METHODS}

Antibodies: Monoclonal antibody to rat $\gamma$-GTP was prepared by hybridoma technology as described previously (32). The hybridoma culture supernatant (designated 5B9) was used for the study. This antibody recognized the heavy subunit of $\gamma$-GTP and its class was IgG $_{1}$. Monoclonal antibodies to human transferrin and prostatic acid phosphatase were obtained from Cosmo Bio. Co. (Tokyo, Japan). Vectastain ABC kits were purchased from Vector Lab. Inc.

Immunohistochemistry: Under Nembutal anesthesia, adult male Wistar rats were perfused with PBS $(0.01 \mathrm{M}$ phosphate buffer, $\mathrm{pH} 7.2$, containing $0.85 \% \mathrm{NaCl})$ for $5 \mathrm{~min}$, and successively with $500 \mathrm{ml}$ of cold PLP (periodate-lysine-paraformaldehyde) fixative (21). The kidney was cut into small blocks and the blocks were further fixed in the same fixative for $6 \mathrm{hr}$ at $4^{\circ} \mathrm{C}$ with a gentle shaking. The blocks were then washed with $7.5 \%$ sucrose/PBS overnight at $4^{\circ} \mathrm{C}$. Approximately $40 \mu \mathrm{m}$ thick sections were prepared with a microslicer (Dosaka EM Co., Kyoto). The sections were treated in $7.5 \%$ sucrose $/ \mathrm{PBS}$ at $90^{\circ} \mathrm{C}$ for $5 \mathrm{~min}$ in order to unmask the hidden determinant of the $\gamma$-GTP heavy subunit (32). The sections were incubated with $1 \%$ bovine serum albumin (BSA)/PBS for $2 \mathrm{hr}$ in a test tube and then with 5B9 antibody (hybridoma culture supernant) overnight at $4{ }^{\circ} \mathrm{C}$ with gentle shaking. After washing with $7.5 \%$ sucrose/PBS for $3 \mathrm{hr}$, the sections were treated with biotinylated anti-mouse IgG dissolved in $1 \% \mathrm{BSA} / \mathrm{PBS}$ for $8 \mathrm{hr}$ at $4^{\circ} \mathrm{C}$. The sections were washed with $7.5 \%$ sucrose/PBS for $2 \mathrm{hr}$ and successively incubated with $\mathrm{ABC}$ dissolved in $1 \%$ BSA/PBS for $6 \mathrm{hr}$. They were then washed with $7.5 \%$ sucrose/PBS for $2 \mathrm{hr}$. The sections were fixed with $1 \%$ glutaraldehyde/PBS for $30 \mathrm{~min}$ and subsequently wahsed with PBS. They were incubated with $0.025 \% 3,3^{\prime}$-diaminobenzidine-4HCl/0.05 M

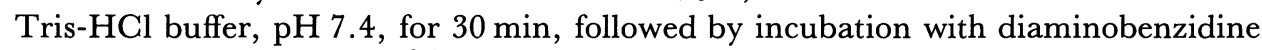
solution containing $0.0025 \% \mathrm{H}_{2} \mathrm{O}_{2}$. After washing with $\mathrm{PBS}$, the sections were postfixed with $2 \% \mathrm{OsO}_{4} / 0.1 \mathrm{M}$ phosphate buffer, $\mathrm{pH} 7.2$, for $30 \mathrm{~min}$ at $4^{\circ} \mathrm{C}$, washed with PBS, dehydrated in a graded ethanol series, treated with QY-1 and finally embedded in epoxy resin. Ultrathin sections were observed under a JEOL $200 \mathrm{CX}$ electron microscope operated at $80 \mathrm{KV}$ without electron staining. The following control experiments were carried out: 1) omission of the primary monoclonal antibody, and 2) substitution of the primary antibody with monoclonal antibodies to human transferrin, human prostatic acid phosphatase and spent culture medium of the myeloma cells.

For light microscopic observation, the tissue blocks were embedded in paraffin, and the localization of the rat $\gamma$-GTP was determined by the ABC method (11) as described previously (32). 


\section{RESULTS}

A strong immunoreaction was recognized along the brush borders of the proximal tubular cells (Figs. 1, 2). Reaction products were also seen along the invaginations of the apical plasma membrane and in the small vacuoles of the apical cytoplasm (Fig. 1). No reaction products were observed in the tight junctions (Figs. 1, 2). The proximal tubules of the $S_{3}$ segments (straight portion; Fig. 2) provided the strongest immunostaining and the $S_{1}$ segments (convoluted portion) exhibited the weakest reaction. The proximal tubules of the juxtamedullary nephrons revealed stronger $\gamma$-GTP immunostaining than those of the cortical nephrons. A conspicuous reaction was recognized along the basal interdigitating cell processes and lateral cell membranes of the proximal tubules (Figs. 1-4). Such immunostaining of the basolateral cell membranes was prominent in the $S_{2}$ and $S_{3}$ segments, however, no reaction was recognized along the basolateral membrane of the epithelial cells of the $S_{1}$ segment.

The cells of the descending thin limbs of Henle's loops also displayed immunostaining of $\gamma$-GTP along the apical plasma membrane (Fig. 5a, b). The reaction was recognized only in the thin limbs of the outer medulla.

A faint reaction was occasionally observed along the apical cell membrane of the distal convoluted tubular cells (Fig. 6). The cells of the macula densa also exhibited weak staining on the apical cell membrane. However, the distal tubules of the medulla revealed no immunoreaction. No specific reaction was noted in the glomeruli, collecting ducts or blood vessels, including the capillaries. All controls showed negative staining except for the erythrocytes, which had endogenous peroxidase activity (data not represented).

\section{DISCUSSION}

In this study, tissue sections were treated with $7.5 \%$ sucrose $/ \mathrm{PBS}$ at $90^{\circ} \mathrm{C}$ for 5 min to expose the hidden antigenic determinant of the heavy subunit and to ensure strong immunostaining. However, this heat treatment procedure did not affect the fine structure of the cells, as demonstrated in the figures represented in this paper. The indirect method using peroxidase labeled antibody also revealed almost the same staining patterns in the proximal tubules and descending thin limbs of Henle's loops, although the intensity of the immunostaining was weaker than that obtained by the $\mathrm{ABC}$ method: reaction products were not recognized in the distal tubules.

$\gamma$-GTP was localized mainly along the brush borders of the proximal tubules (Figs. 1, 2). Recent light and electron microscopic studies have indicated that the proximal tubules of the rat kidney consists of three segments, the $S_{1}, S_{2}$ and $S_{3}$ segments $(18,19)$. The immunostaining of $\gamma$-GTP in the segments of the proximal tubules was heterogeneous, i.e. the strongest reaction was recognized in the $\mathrm{S}_{3}$ segment. These observations were in accordance with those of immunohistochemical studies using polyclonal antibody and of enzyme histochemical studies $(13,14,23)$. Heinle et al. (9) also reported that the $\gamma$-GTP activity was highest in the $\mathrm{S}_{3}$ segment by employing a microdissection technique of single nephron. Spater et al. $(13,28)$ found that segmental heterogeneity in the proximal tubules was recognizable by the enzyme histochemical method but not by the immunohistochemistry with protein A labeled peroxidase. The reason for the discrepancy between the two techniques remains 

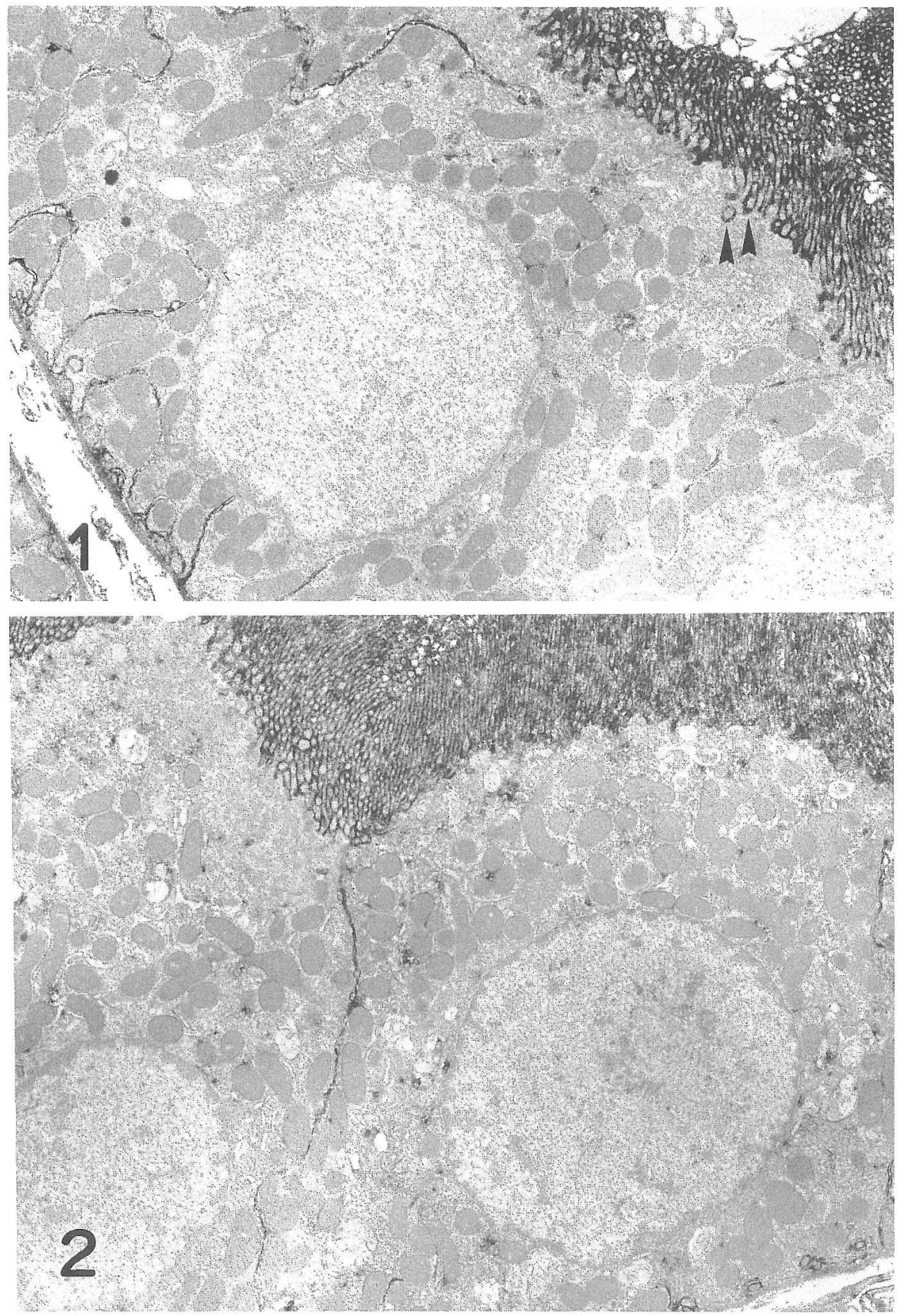

FIG. 1. Proximal tubule $\left(\mathrm{S}_{2}\right.$ segment) of the rat kidney immunostained with monoclonal antibdoy to rat $\gamma$-GTP. Reaction products are observed along the brush border, basolateral membrane and in the apical invaginations. No reaction is seen in the tight junctions. Arrow heads indicate the invaginations of the apical cell membrane. $\times 7,200$

FIG. 2. Proximal tubule of the $S_{3}$ segment. Positive immunoreaction is recognized along the brush border and basolateral cell membrane. The basement membrane exhibits no immunostaining. $\times 7,300$ 

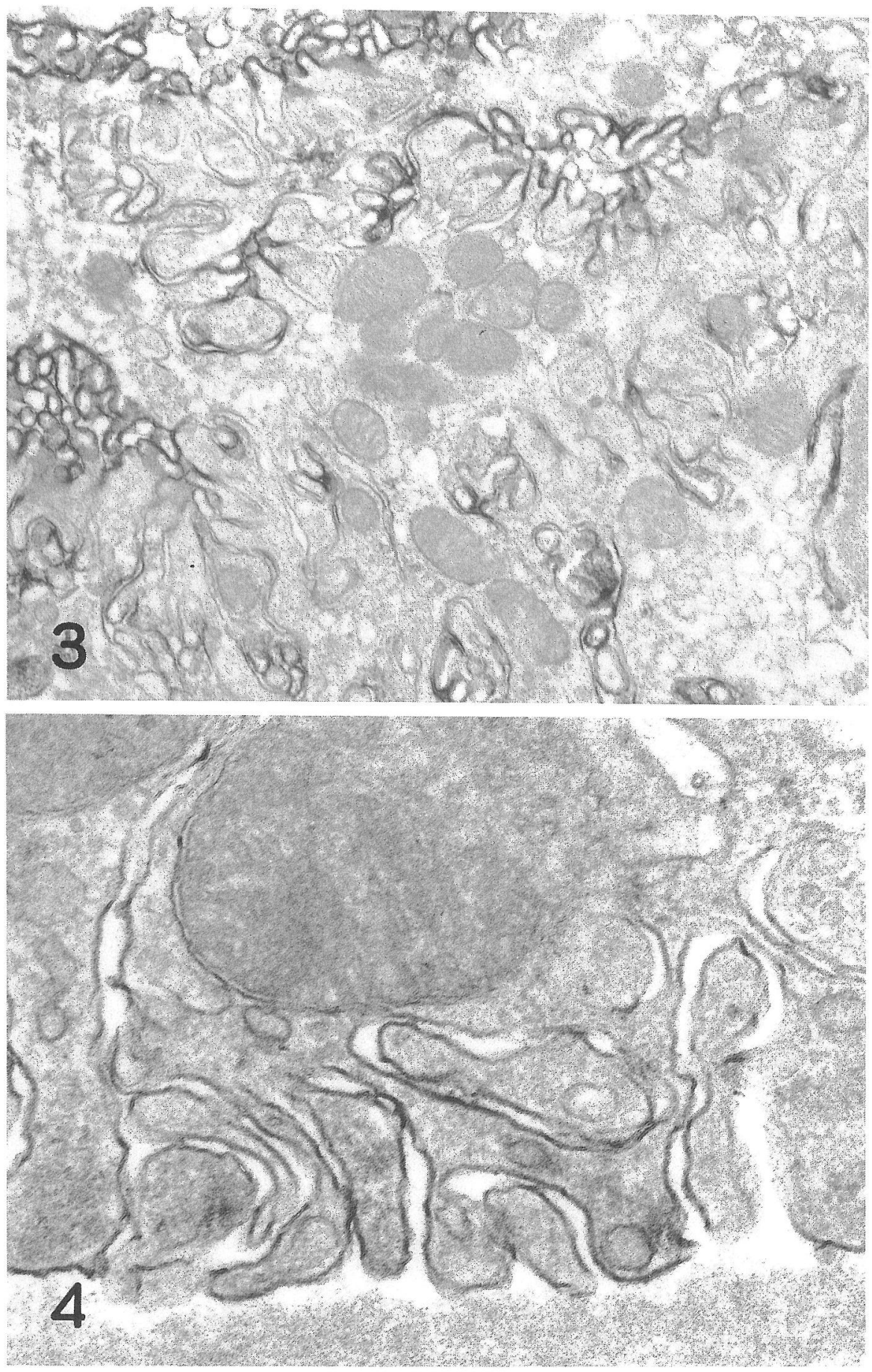

FIG. 3. Tangential section of the basal portion of a proximal tubule. Reaction deposits are present along the interdigitated basal cell membrane (basal labyrinth). $\quad \times 19,700$

FIG. 4. Basal portion of a proximal tubule. $\gamma$-GTP is localized along the interdigitating cell processes but not in the basement membrane. $\times 63,000$ 

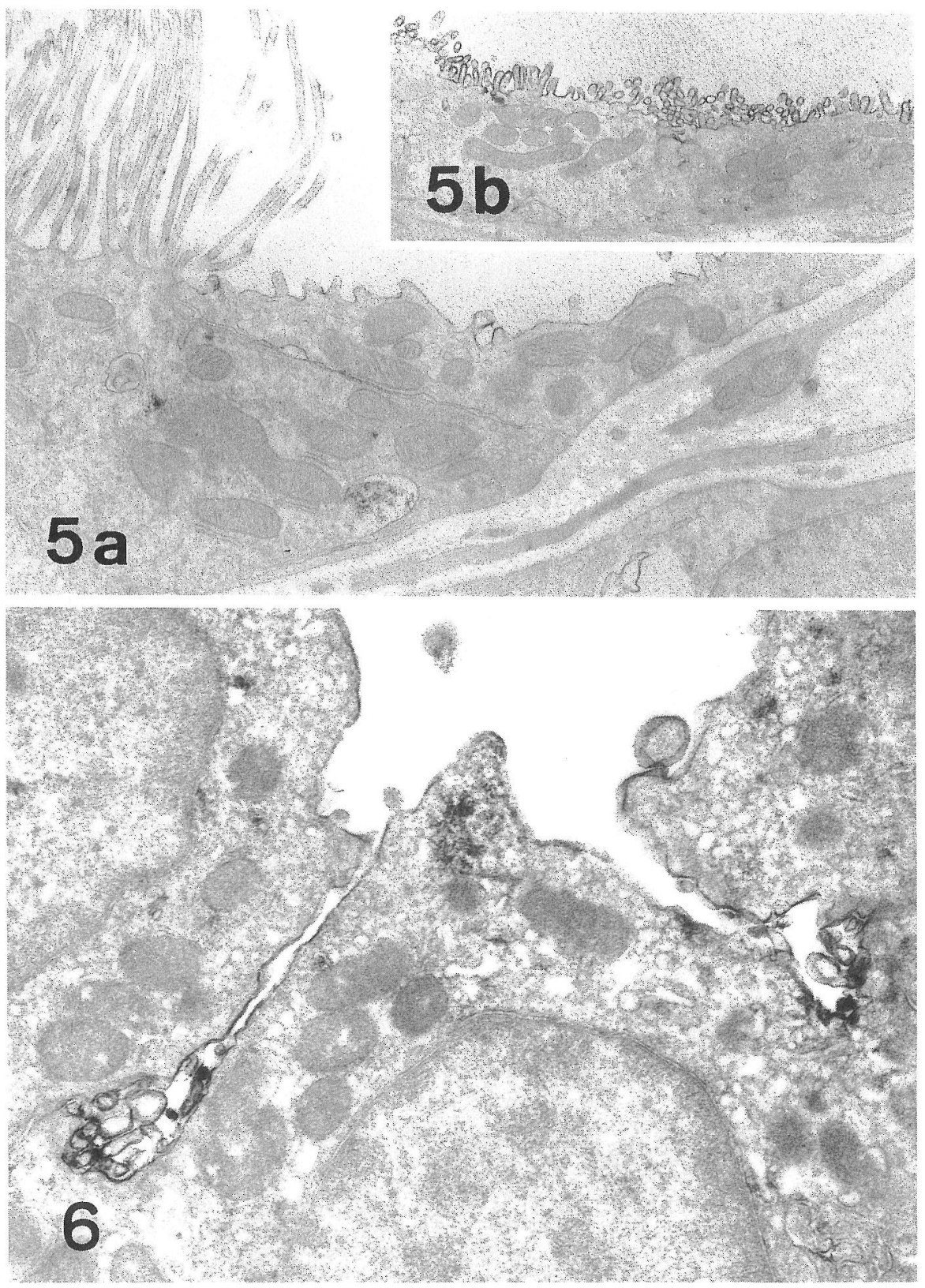

Fig. 5. Descending thin limb of Henle's loop: a; transitional part from the proximal tubule to the descending thin limb, b; upper part of the thin limb (long loop). The luminal cell membrane reveals positive reaction products. $\mathrm{a} ; \times 12,200, \mathrm{~b} ; \times 5,200$

Fig. 6. Distal convoluted tubule. Weak immunoreaction is seen along the luminal cell membrane. $\times 14,700$ 
unclear.

The basolateral cell membranes of the $S_{3}$ and $S_{2}$ segments also exhibited a positive immunoreaction for $\gamma$-GTP in our study, as reported in earlier immunohistochemical studies on the rat $(23,28,32)$. Enzyme histochemical investigations have proved the localization of $\gamma$-GTP in the basolateral membranes, i.e. $\gamma$-GTP enzyme activity was observed there (12, our unpublished data). Such basolateral localization of $\gamma$-GTP in the proximal tubules has also been recognized in the neonatal rat kidney (our unpublished observations), as well as in the human kidney where $\gamma$ GTP was demonstrated by using monoclonal antibody against human $\gamma$-GTP purified from human kidney (26).

Glutathione is synthesized in many tissues from its constituent amino acids and secreted into the extracellular space (3). More than $80 \%$ of the plasma glutathione is extracted in a single pass through the kidney, although glomerular filtration may account for about $30 \%$ of its extraction through $\gamma$-GTP and peptidases of the luminal membranes $(1,24,27)$. The residual glutathione extraction may thus be mainly due to $\gamma$-GTP localized in the basolateral membranes of the proximal tubules as suggested by earlier investigators $(1,2,23,24,28)$. It is unclear from the results of the present study whether the presence of the enzyme along the basolateral membrane indicates possible transport of amino acids or polypeptides from the blood vessels into the epithelial cells or vice versa. However, at least, the basolateral membrane was found to be involved in the metabolism of $\gamma$-glutamyl moieties and amino acids as well as polypeptides.

\section{REFERENCES}

1. Abbott, W. A., Bridges, R. J. and Meister, A.: Extracellular metabolism of glutathione accounts for its disappearance from the basolateral circulation of the kidney. J. Biol. Chem. 259; 15393-15400, 1984

2. Anderson, M. E., Bridges, R. J. and Meister, A.: Direct evidence for inter-organ transport of glutathione and that the non-filtration renal mechanism for glutathione utilization involves $\gamma$ glutamyl transpeptidase. Biochem. Biophys. Res. Commun. 96; 848-853, 1980.

3. Curthoys, N. P.: Interorgan flux of glutathione. Fed. Proc. 45; 2166-2169, 1986.

4. George, S. G. and Kenny, A. J.: Studies on the enzymology of purified prepatation of brush border from rabbit kidney. Biochem. J. 134; 43-57, 1973.

5. Glenner, G. G. and Folk, J. E.: Glutamyl peptidases in rat and guinea pig kidney slices. Nature 192; 338-340, 1961.

6. Glossman, H. and Neville, D. M.: $\gamma$-Glutamyltransferase in kidney brush border membranes. FEBS Lett. 19; 340-344, 1972.

7. Gossrau, R.: Investigation of proteinases in the digestive tract using 4-methoxy-2naphthylamine (MNA) substrate. J. Histochem. Cytochem. 29; 464-480, 1981.

8. Griffith, O.W. and Meister, A.: Translocation of intracellular glutathione to membrane bound $\gamma$-glutamyltranspeptidase as a discrete step in the $\gamma$-glutamylcycle: glutathionuria after inhibition of transpeptidase. Proc. Natl. Acad. Sci. U.S.A. 76; 268-272, 1979.

9. Heinle, H. and Wendel, A.: The activities of the key enzymes of the $\gamma$-glutamylcycle in microdissected segments of the rat nephrone. FEBS Lett. 73; 220-224, 1977.

10. Horiguchi, S., Inoue, M. and Morino, Y.: $\gamma$-Glutamyltranspeptidase: Sideness of its active site on renal brush-border membrane. Eur. J. Biochem. 87; 429-437, 1978.

11. Hsu, S.-M., Raine, L. and Fanger, H.: Use of avidin-biotin-peroxidase complex (ABC) in immunoperoxidase techniques: A comparison between ABC and unlabeled antibody (PAP) procedures. J. Histochem. Cytochem. 29; 577-580, 1981. 
12. Hughey, R. P. and Curthoys, N. P.: Comparison of the size and physical properties of $\gamma$ glutamyltranspeptidase purified from rat kidney following solubilization with papain or with Triton X-100. J. Biol. Chem. 251; 7863-7870, 1976.

13. Inoue, M.: Interorgan metabolism and transport of glutathione. Protein, Nucleic Acid and Enzyme 29; 695-707, 1984 (in Japanese).

14. Jedrzejewsky, K. and Kugler, P.: Peptidases in the kidney and urine of rats after castration. Histochemistry 74; 63-84, 1982.

15. Kugler, P.: Localization of aminopeptidase A (angiotensinase A) in the rat and mouse kidney. Histochemistry 72; 269-278, 1981.

16. Lojda, Z., Gossrau, R. and Schiebler, T. H.: Enzyme Histochemistry, Springer, Berlin, 1979, pp. 207-212.

17. Marathe, G. V., Nash, B., Haschemeyer, R. H. and Tate, S. S.: Ultrastructural localization of $\gamma$-glutamyltranspeptidase in rat kidney and jejunum. FEBS Lett. 107; 436-440, 1979.

18. Maunsbach, A. B.: Observations on the segmentation of the proximal tubule in the rat kidney. Comparison of results from phase contrast, fluorescence and electron microscopy. J. Ultrastrut. Res. 16; 239-258, 1966.

19. Maunsbach, A. B.: Ultrastructure of the proximal tubule. In Handbook of Physiology, Section 8, Renal Physiology, American Physiological Society, Washington, 1973, pp. 31-79.

20. Meister, A., Tate, S. S. and Griffith, O. W.: $\quad \gamma$-Glutamyltranspeptidase. In Methods in Enzymology, vol. 77, ed. W. B. Jakoby, Academic Press, New York, 1981, pp. 237-253.

21. McLean, I. W. and Nakane, P. K.: Periodate-lysine-paraformaldehyde fixative. A new fixative for immunoelectron microscopy. J. Histochem. Cytochem. 22; 1077-1083, 1974.

22. Nash, B. and Tate, S. S.: Biosynthesis of rat renal $\gamma$-glutamyl transpeptidase. Evidence for a common precursor of the two subunits. J. Biol. Chem. 257; 585-588, 1982.

23. Pfaller, W., Gstraunthaler, G., Katanko, H. and Curthoys, N. P.: Immunocytochemical localization of $\gamma$-glutamyl-transferase on isolated renal cortical tubular fragments. Histochemistry 80; 289-293, 1984.

24. Rankin, B. B. and Curthoys, N.P.: Evidence for the renal paratubular transport of glutathione. FEBS Lett. 147; 193-196, 1982.

25. Rutenburg, A. M., Kim, H., Fishbein, J. W., Hanbeer, J. S., Wasserkrug, H. L. and Seligman, A. M.: Histochemical and ultrastructural demonstration of $\gamma$-glutamyl transpeptidase activity. J. Histochem. Cytochem. 17; 517-526, 1969.

26. Shiozawa, M., Yamashita, S., Aiso, S. and Yasuda, K.: A monoclonal antibody against human kidney gamma-glutamyl transpeptidase: Preparation, immunochemical and immunohistochemical characterization. J. Histochem. Cytochem. (in press) 1989.

27. Silbernagl, S., Pfaller, W., Heinle, M. and Wendel, A.: Topology and function of renal $\gamma$ glutamyl transpeptidase. In Functions of Glutathione in Liver and Kidney, ed. by M. Sies and A. Wendel. Springer, Berlin, 1978, pp. 60-69.

28. Spater, H. W., Poruchynsky, M. S., Quintana, N., Inoue, M. and Novikoff, A. B.: Immunocytochemical localization of $\gamma$-glutamyltransferase in rat kidney with protein Ahorseradish peroxidase. Proc. Natl. Acad. Sci. U.S.A. 79; 3547-3550, 1982.

29. Taniguchi, N., Yokosawa, N., Iizuka, S., Sako, F., Tsukada, Y.a nd Satoh, M.: $\gamma$-Glutamyl transpeptidase of rat liver and hepatoma tissues: An enzyme immunoassay and immunostaining studies. Ann. N. Y. Acad. Sci. 417; 203-212, 1983.

30. Tate, S. S. and Meister, A.: Affinity labeling of $\gamma$-glutamyl transpeptidase and localization of $\gamma$-glutamyl binding site on the light subunit. Proc. Natl. Acad. Sci. U.S.A. 74; 931-935, 1977.

31. Tsuji, A., Matsuda, Y. and Katunuma, N.: The conversion of the precursor form of $\gamma$ glutamyltranspeptidase to its subunit form takes place in brush border membane. J. Biochem. 87; 1567-1571, 1980.

32. Yasuda, K., Yamashita, S., Aiso, S., Shiozawa, M. and Komatsu, T.: Immunohistochemical study of $\gamma$-glutamyltranspeptidase with monoclonal antibodies. I. Preparation and characteristics of monoclonal antibodies to $\gamma$-glutamyl transpeptidase. Acta histochem. cytochem. $19 ; 589-600.1986$. 